\title{
Relationship between the Change in Health Status and Satisfaction with Physical Education in Chinese College Students
}

\author{
Xuelian Wang, Yoshio Sugiyama \\ Faculty Human-Environment Studies, Kyushu University, Fukuoka, Japan \\ Email: xuelian1984322@yahoo.co.jp
}

Received 5 June 2014; revised 8 July 2014; accepted 20 July 2014

Copyright (C) 2014 by authors and Scientific Research Publishing Inc.

This work is licensed under the Creative Commons Attribution International License (CC BY). http://creativecommons.org/licenses/by/4.0/

\begin{abstract}
We examined the relationship between health status and satisfaction with physical education (PE) lessons. The participants $(\mathrm{N}=142$, Mean $=19.14 \mathrm{yrs}, \mathrm{SD}=0.92)$ were university students in China. The participants completed questionnaires at the beginning and end of the PE class term to indicate their health status. Multiple linear regression analyses revealed that the changes in health status significantly correlated with satisfaction with PE lessons. Results of the multiple regression analyses indicated that satisfaction with PE lessons was significantly related to enjoyment. The practical implications of this study focused on developing a PE lesson program that would improve the health status of students well as be enjoyable to the students.
\end{abstract}

\section{Keywords}

Health Status, Satisfaction, Physical Education, College Students

\section{Introduction}

China has witnessed significant socioeconomic and cultural changes over the last decade, and these changes have influenced the lifestyle and habits of college students. Recently, there has been an increased focus on health status, mental, social and physical health of Chinese college students. A recent health survey of Chinese college students indicated that $65.68 \%$ of college students did not exercise, and $40 \%$ of them were not satisfied with their health status (Wang, 2009). Although there are many studies on the health status and lifestyle of university students, several of them only examine the relationship between lifestyle and mental health (Li \&Wang, 2007; Ma, Yang, \& Wang, 2009; Mao, 2009; Margareta, 2005).

While several studies have evaluated the importance of social health among Chinese college students, the 
WHO (2009) defines health as "a state of complete physical, mental and social well-being and not merely the absence of disease or infirmity”. Social health, one of three fundamental aspects of overall health, refers to being able to adequately interact with people and/or wider society, such as communicating effectively with others, helping others, and being well adapted. Given that social health contributes to overall health status, it is therefore necessary not only to pay attention to physical and mental health, but also to recognize the importance of social health. Despite this, to date no studies have investigated how health (i.e. social, mental, or physical health) could be improved using physical education (PE) lessons. In order to implement such improvements, China's Ministry of Education issued the "National College Physical Education Curriculum Guide". This guide intended to explore the direction of reform of college sports and PE building from a modern perspective. It reported that the reform of the PE curriculum would require teachers to discontinue using traditional PE concepts and roles, and establish a new PE philosophy, with health as its first priority (Mao, 2009).

Much of the existing research has discussed PE lessons. PE as a subject has taken on a new role in school education. (Pearman 11l, Valois, Sargent, Saunders, Deane, \& Macera, 2014) found that PE lessons can create an opportunity to conduct health promotion activities for older adolescents. In their study, 59\% of the students suggested that physical education should be designed to improve health. Moreover, the alumni who had requested for PE lessons were more likely to do some exercise such as running and swimming.

PE can be very useful for promoting healthy lifelong exercise habits among young people. In school, PE provides an opportunity for regular, structured physical activity. The US government's "Health of the Nation" targets are an example of the important role played by PE in improving physical activity (Fairclough \& Stratton, 2005). A Japanese study also indicated that it was important for university students to maintain their health and to improve their lifestyle through PE lessons and sports (Tokunaga \& Hashimoto, 2002).

Meanwhile, PE plays an important role in school education. It can provide students with a chance to feel happy, learn new sports, and interact with others. According to the "National College Physical Education Curriculum Guide", emphasis should be placed on making physical education lessons enjoyable and leaving students satisfied. However, different people have different factors affecting satisfaction with their PE lessons. Some people may feel an increased sense of fulfillment and accomplishment and an improved self-image, while others may feel increased satisfaction through their challenges. Therefore, if the object is set as achieving a sense of satisfaction, students will be encouraged in PE lessons. Therefore, this can be viewed as a way to improve physical health; and, the satisfaction of students can be seen as a positive measure indicating the amount of physical activity.

Recently, several studies have discussed the variables of PE lessons, such as students' goal, motivation, motivational climate, and the psychological outcome of physical education (e.g., Chen \& Ennis, 2004; Barkoukis et al., 2008; Standage, Duda, \& Ntoumanis, 2003; Lonsdale, Sabiston, Taylor, \& Ntoumanis, 2011). However, in China, PE lessons focus on practicing a wide range of sports. There was not much consideration about changes in the psychological variables that were related to PE lessons.

We hoped that our work would contribute to the field of physical education, giving PE teachers a new approach in developing models for sports practices. Therefore, in our study, we checked the changes of health status, and discussed the relationship between the change in health status and the satisfaction of students.

\section{Method}

\subsection{Participants and Procedure}

One hundred forty-two students (108 Female and 34 Male) between 17 and 21 years of age (Mean = 19.14; SD = 0.92) participated in the study, that was approved by a university in Dalian, China. Informed consent was obtained from all participants, and the procedure was explained to them. All of the participants were students in their first year at university. PE is a required course, and the students attend one lesson of aerobics every week. This study extended over a period of 5 months from October to February, 2009.

\subsection{Measurements}

Health Status-The health of the subjects was measured using the Diagnostic Inventory of Health and Life Habit (DIHAL.2) scale (Tokunaga, 2003). This scale has been tested and validated successfully for Japanese students. Like the Japanese version, is composed of 47 items under four categories to be answered on a 5-point Li- 
kert-type scale, health status, exercise habits, dietary habits and rest habits. For this study, we only used the 16 items measuring health status. These items are further divided into three subcategories (physical health, mental health, and social health). Total scores range from 12 to 60 points. Four items measure physical health, with total scores ranging from 4 to 20. An example of the items from the category would be, "Do you have enough physical fitness to study or work?” The mental health category consists of 4 items with scores ranging from 4 to 20. An example question from the category is, "Do you adapt to the lifestyle of group?" Finally, there are two items measuring social health, such as "Do you have a friend who can play sports with you?" We translated the Japanese version to Chinese for the students.

Satisfaction with the PE lessons-We used a questionnaire developed by Wang (Wang, 2009) to check if students were satisfied at the end of the lesson. The questionnaire comprises 22 items measuring six factors (sense of fulfillment, accomplishment, self-image, relationships with others, tensionless, and challenges). Total scores can range from 6 to 30 points. Six items measure sense of fulfillment, with a total score that can range from 6 to 30 points. Five items measure accomplishment, with a score that can range from 5 to 25 points. Relationships with others are measured by four items, with a score that can range from 4 to 20. Three items measure self-image, with a score that can range from 3 to 15. Finally, two items measure tensionless and challenges, with a score that can range from 2 to 10 .

The questionnaire begins with the expression, "In the PE lesson during the current term..." and it follows statements like:

-Were you satisfied to play new sports?

-Were you satisfied to make new friends?

-Were you satisfied to think on your own about something?

-Were you satisfied to achieve a mastery of sports?

-Were you satisfied about looking better?

-Were you satisfied about overcoming a feeling of tension?

The statements above include one example from each of the 6 measurement factors. Students responded using a Likert-type scale ranging from completely dissatisfaction (1) to completely satisfaction (5).

\subsection{Data Analysis}

Changes in health status were calculated. To further analyze the relationship between the change in health status and satisfaction with PE, multiple linear regression analyses were performed. All data was analyzed using SPSS 13.0 for Windows.

\section{Results}

\subsection{Validity and Reliability}

The reliability of the scale of health status-We examined the validity of the factors for four indices. The root mean square error of approximating (RMSEA) had a minimum of 0.045 . The GFI index had a fit of 0.935 and AGFI index was 0.901. Each index indicated a good fit. Measures of health status were carried out at the beginning and end of the PE course.

The validity of the scale of satisfaction with PE-The Cronbach's alphas obtained from our results of satisfaction were as follows: alpha $=0.785$ for fulfillment, alpha $=0.764$ for accomplishment, alpha $=0.834$ for selfimage, alpha $=0.802$ for relationships with others, alpha $=0.885$ for tensionless, alpha $=0.871$ for challenges. The alpha coefficient of the overall scale was 0.883 . In this study, the internal consistency of the factors was acceptable for students.

\subsection{The Correlation between the Change in Health Status and the Satisfaction with PE Lesson}

Table 1 summarizes the correlation between the change in health status and the satisfaction with PE lesson. The result of regression analyses revealed that grater change in physical health was related to higher satisfaction with accomplishment, self-image, tensionless, and sense of fulfillment. The change in social health had a significantly positive relationship with accomplishment, relationship with others, tensionless, and a marginally significant relationship with sense of fulfillment. However, the change in mental health correlated negatively correlated 
Table 1. Regression analysis for changes in health status with satisfaction of PE lessons.

\begin{tabular}{ccccccc}
\hline \multirow{2}{*}{$\begin{array}{c}\text { The change of } \\
\text { health status }\end{array}$} & \multicolumn{5}{c}{ Satisfaction of PE lessons } \\
\cline { 2 - 7 } & Challenges & Accomplishment & Self-image & Relationships with others & Tensionless & $\begin{array}{c}\text { Sense of } \\
\text { fulfillment }\end{array}$ \\
\hline Physical health & 0.124 & $0.315^{* *}$ & $0.210^{*}$ & 0.146 & $0.263^{* *}$ & 0.141 \\
Mental health & 0.084 & 0.008 & 0.127 & $-0.216^{* *}$ & -0.050 & -0.102 \\
Social health & 0.099 & $0.225^{* *}$ & 0.118 & $0.177^{*}$ & $0.212^{*}$ & $0.178 \dagger$ \\
$\mathrm{R}^{2}$ & 0.045 & 0.215 & 0.100 & 0.117 & 0.166 & 0.082 \\
\hline
\end{tabular}

Note: $\dagger p<0.10,{ }^{*} p<0.05,{ }^{* *} p<0.01$.

with satisfaction of relationship with others.

\section{Discussion}

In this study, we hypothesized that there would be a positive correlation between the change in health status and satisfaction with PE. The results of this study indicated that changes in physical health related positively to satisfaction with PE. The physical activity involved in PE lessons may be a factor improving physical health, and may increase students' sense of accomplishment. The study sample performed aerobic activities during their lessons, and therefore, there was a significant relationship between the change in their physical health and their satisfaction with self-image. There was almost no relationship between changes in mental health and satisfaction with PE lessons.

According to previous research, most results indicated no significant correlation between mental health and satisfaction. However, it should be noted that in this study mental health related negatively to the relationship with others. Specifically, students who did not adapt well to the group, were unable to make new friends, cooperate with others, and deepen their trust towards others; and those who became anxious more were not satisfied with the number of friends they made in PE lessons. This means that the greater the changes in physical and social health were, the lower were the scores of satisfaction with PE lessons. This could have resulted from the students' expectation that they would from new friends faster in PE class than they did before they became part of it. However, they may not have been able to create as many friendships as they had expected by the end of class. The causality of this result cannot be interpreted with surety from the finding and would remain a question in the present study. It is recommended that future research looks at studying the factors that affect mental health to test whether mental health has any significant relationship with PE.

Changes in social health were significantly related to the students' satisfaction with their relationships with others. According to this result, PE may provide opportunities to increase interaction with others. Thus, the present study supports the suggestion that the change in health status is an effective method to enhance satisfaction of students. Furthermore, other studies have suggested the importance of improving the health status of students using PE (Tokunaga \& Yamazaki, 2008).

\section{Conclusion}

In conclusion, previous studies have not yet identified a significant correlation between changes in health status and satisfaction with PE lessons, but, the findings of this study empirically support traditional Chinese health beliefs. In accordance with the Health Education Policy of The Chinese Government (Ma, Yang \& Wang, 2009), the current health status of university students in China is still being researched. However, the necessity of PE in universities for the purpose of improving students’ health must be emphasized by future studies (Mao, 2009). There were many studies focusing largely on the relationship between the psychological variable and physical education, which included factors like attitude, enjoyment, intrinsic motivation, and concentration (Ferrer-Caja \& Weiss, 2000; Hassandra, Goudas, \& Chroni, 2003; Koka, 2003). If gained the positively outcomes in PE lessons, maybe motivation of sports/exercise would be enhanced in their life. However, no study has yet focused on assessing students' satisfaction with PE lessons. The present study not only established that satisfaction with lessons related to change in health, but also involved an approach for developing models that could be applied to future PE lessons at university. 


\section{References}

Barkoukis, V., Tsorbatzoudis, H., \& Grouios, G. (2008). Manipulation of Motivational Climate in Physical Education: Effects of a Seven-Mouth Intervention. European Physical Education Review, 4, 367-387. http://dx.doi.org/10.1177/1356336X08095671

Chen, A., \& Ennis, A. (2004). Goals, Interests, and Learning in Physical Education. The Journal of Educational Research, 97, 329-338. http://dx.doi.org/10.3200/JOER.97.6.329-339

Fairclough, S., \& Stratton, G. (2005) Physical Education Makes You Fit and Healthy • Physical Education’s Contribution to Young People’s Physical Activity Levels. Health Education Research, 1, 14-23.

Ferrer-Caja, E., \& Weiss, M. (2000). Predictors of Intrinsic Motivation among Adolescent Students in Physical Education. American Alliance for Health, Physical Education, Recreation and Dance, 71, 267-279.

Hassandra, M., Goudas, M., \& Chroni, S. (2003). Examining Factors Associated with Intrinsic Motivation in Physical Education: A Qualitative Approach. Psychology of Sport and Exercise, 4, 211-223. http://dx.doi.org/10.1016/S1469-0292(02)00006-7

Koka, A., \& Hein, V. (2003). Perceptions of Teacher's Feedback and Learning Environment as Predictors of Intrinsic Motivation in Physical Education. Psychology of Sport and Exercise, 4, 333-346. http://dx.doi.org/10.1016/S1469-0292(02)00012-2

Li, P., \& Wang, Y. (2007). A Study on Relationship between Lifestyle and Mental Health of College Students. Proceedings of The 12th East Asia Sports Exercise Science Society Annual Conference, 12, 12-22.

Lonsdale, C., Sabiston, C., Taylor, L., \& Ntoumanis, N. (2011). Measuring Student Motivation for Physical Education: Examining the Psychometric Properties of the Perceived Locus of Causality Questionnaire and the Situational Motivation Scale. Psychology of Sport and Exercise, 12, 284-292 http://dx.doi.org/10.1016/j.psychsport.2010.11.003

Ma, H.X., Yang, H. L., \& Wang, M. (2009). Physical Education and Health Status in University. Beijing: Aero Industry Publication Company.

Mao, Z (2009). View for Physical Education and Health Education. Beijing: Physical Education and Health Status.

Margareta, I. K. (2005). Gender Differences in Health Habits and in Motivation for a Healthy Lifestyle among Swedish University Students. Nursing and Health Science, 7, 107-118. http://dx.doi.org/10.1111/j.1442-2018.2005.00227.x

Pearman III, S., Valois, R., Sargent, R., Saunders, R., Drane, J., \& Macera, C. (2014). The Impact of a Required College Health and Physical Education Course on the Health Status of Alumni. Journal of American College Health, 46, 77-85. http://dx.doi.org/10.1080/07448489709595591

Standage, M., Duda, J., \& Ntoumanis N. (2003). A Model of Contextual Motivation in Physical Education: Using Constructs From Self-Determination and Achievement Goal Theories to Predict Physical Activity Intentions. Journal of Educational Psychology, 95, 97-110. http://dx.doi.org/10.1037/0022-0663.95.1.97

Tokunaga, K. (2003). Diagnostic Inventory of Health and Life Habit (DIHAL.2) Scale. Fukuoka: Toyo Physical Corporation.

Tokunaga, K., \& Hashimoto, K. (2002). Effects of Life Habits of Young People on Their Health levels Assessed. Journal of Health Science, Kyushu University, 24, 39-46.

Tokunaga, K., \& Ymazaki, S. (2008). Improvement of Health Status and Lifestyle through Health Course of Health and Physical Education. Journal of Fukuoka Social Medical Welfare University, 5, 97-108.

Wang, X. L. (2009). Research for Health Status /Lifestyle and the Expectation through the PE Lessons of College Students in China. Master Thesis. Graduate School of Human Environment Studies, Kyushu University.

WHO (2009). Basic Documents (47th ed.). World Health Organization. http://apps.who.int/gb/bd/PDF/bd47/EN/basic-documents-47-en.pdf 
Scientific Research Publishing (SCIRP) is one of the largest Open Access journal publishers. It is currently publishing more than 200 open access, online, peer-reviewed journals covering a wide range of academic disciplines. SCIRP serves the worldwide academic communities and contributes to the progress and application of science with its publication.

Other selected journals from SCIRP are listed as below. Submit your manuscript to us via either submit@scirp.org or Online Submission Portal.
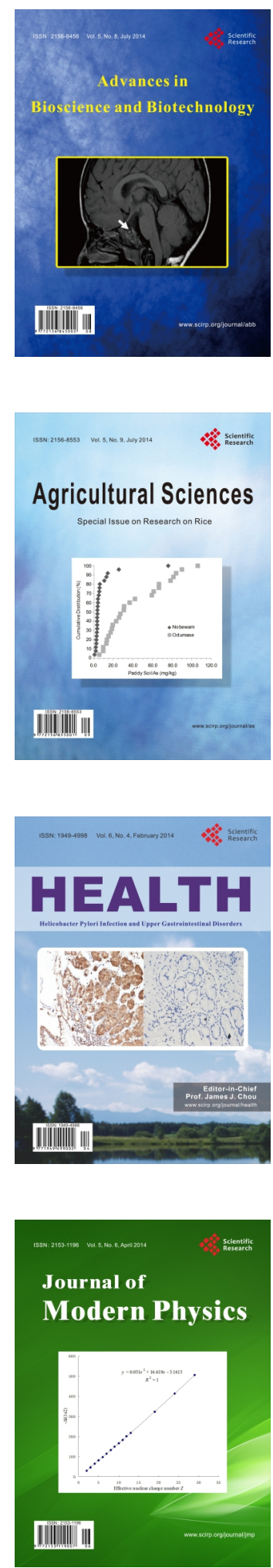
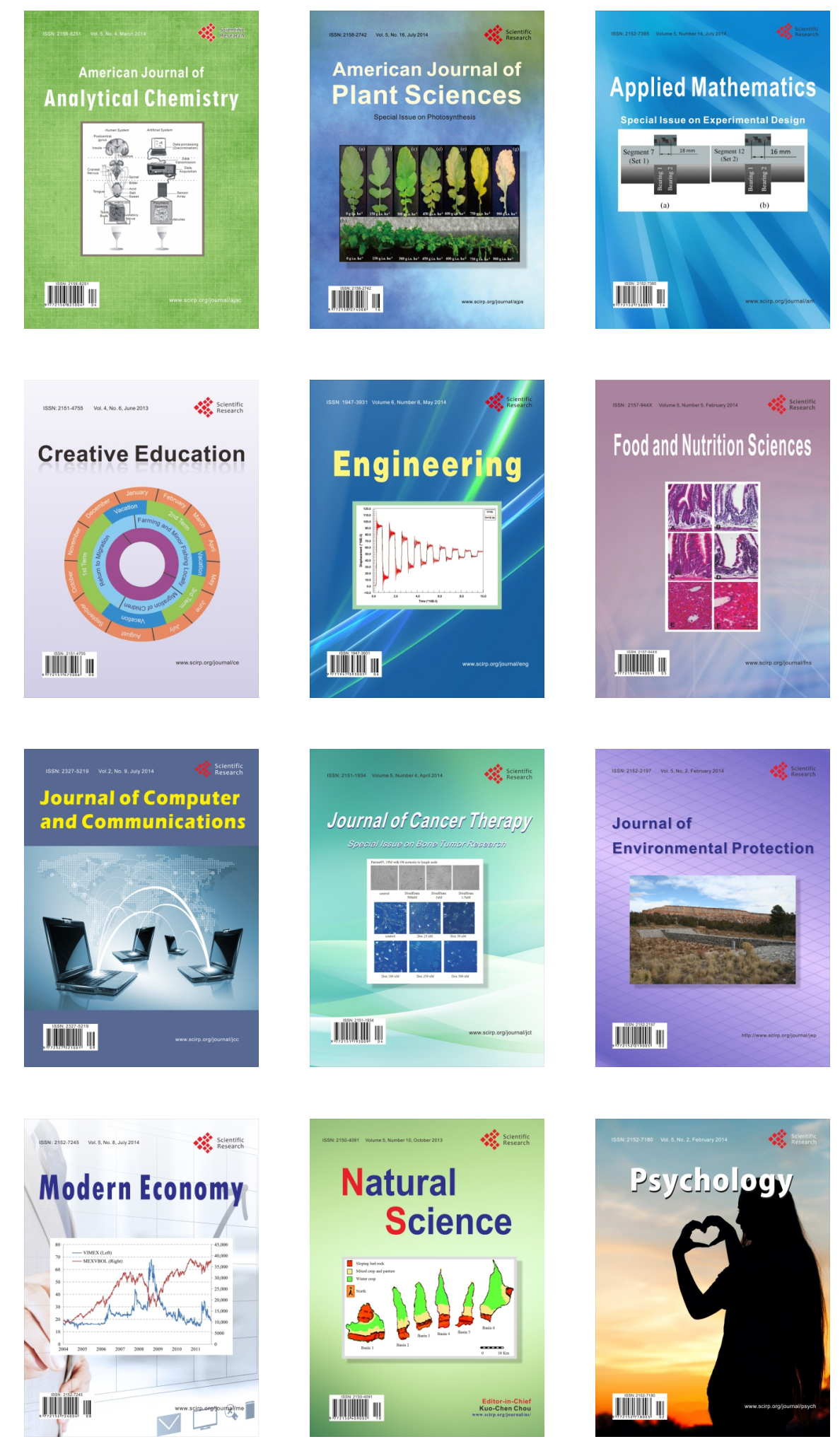